\title{
Impact of Anemia on Mortality and Nutritional Recovery among Hospitalized Severely Malnourished Children in Burkina Faso
}

\author{
Léon G. Blaise Savadogo, ${ }^{12}$, Ivone Zoetaba ${ }^{3}$, Bernard Ilboudo', Maurice Kinda1, \\ Philipe Donnen 4 \\ ${ }^{1}$ Department of Epidemiology and Public Health, Child and Mother Health, Nutrition and Survival Unit, Institut \\ Supérieur des Sciences de la Santé, Université Polytechnique de Bobo Dioulasso, Bobo Dioulasso, Burkina Faso \\ ${ }^{2}$ CR2, Epidemiology, Biostatistics-Clinical Research, School of Public Health, Université Libre de Bruxelles, \\ Bruxelles, Belgique \\ ${ }^{3}$ Centre de Réhabilitation Nutritionnelle, Ouagadougou, Burkina Faso \\ ${ }^{4}$ CR3, Politiques et Systèmes de Santé, Santé Internationale, Ecole de Santé Publique, Université Libre de \\ Bruxelles, Bruxelles, Belgique \\ Email: gueswende@hotmail.com
}

Received 24 February 2014; revised 18 March 2014; accepted 25 March 2014

Copyright (C) 2014 by authors and Scientific Research Publishing Inc.

This work is licensed under the Creative Commons Attribution International License (CC BY).

http://creativecommons.org/licenses/by/4.0/

(c) $\underset{\mathrm{EY}}{\mathrm{B}}$ Open Access

\section{Abstract}

This study aimed to analyze the impact of anemia on mortality rate and nutritional recovery, during severely malnourished inpatient treatment. Material and Methods: This was a retrospective cohort study conducted from data of severely malnourished children hospitalized at a feeding the rapeutic center. Pearson's Chi square test, General linear model, Mortality relatives risks, KaplanMeir survival curves have been used. Results: At admission, $85.3 \%$ of included malnourished children had anemia ( $\mathrm{Hb} \leq 11 \mathrm{~g} / \mathrm{dl})$ and $10.6 \%$ severe anemic $(\mathrm{Hb}<6 \mathrm{~g} / \mathrm{dl})$. Mortality rate did not differed significantly from severely malnourished children with anemia (12.4\%) and without anemia (22.2\%), $p=0.12$. Kaplan Meir survival curves did not differed significantly between the two groups, $(p$ Log Rank $=0.11)$. From admission to discharge, anthropometric Z-scores means evolution did not differed significantly between severely malnourished children with and without anemia at admission. But anthropometric Z-scores means evolution differed significantly within each group's subjects: WHZ (between groups: $p=0.74$; within subjects: $p<0.001$ ), and WAZ (between groups: $p=0.54$; within subjects: $p<0.001$ ). Conclusion: With a strong respect of current recommendation of anemia treatment of inpatient severely malnutrition management, there is no

"Corresponding author.

How to cite this paper: Savadogo, L.G.B., et al. (2014) Impact of Anemia on Mortality and Nutritional Recovery among Hospitalized Severely Malnourished Children in Burkina Faso. Open Journal of Pediatrics, 4, 115-120. 
increased mortality rate in SAM anemic group; and nutritional recovery is significant within subjects of SAM anemic and non anemic children, without difference between groups.

\author{
Keywords
}

Anemia; Mortality; Nutritional Recovery; Severely Malnourished; Children

\title{
1. Introduction
}

In low income countries, severe acute malnutrition (SAM) remains a major killer of children under five years of age. Anemia is common between severely malnourished children [1]-[3] and severe anemia is a medical emergency. Currently, for inpatient treatment, it is strongly recommended not to add iron during treatment initial phase (stabilization phase). Prescribing iron to treat anemia, in the initial phase of the treatment, increases the death. A blood transfusion is required for $\mathrm{Hb}<4 \mathrm{~g} / \mathrm{dl}$ or if $\mathrm{Hb}$ is between $4-6 \mathrm{~g} / \mathrm{dl}$ and if there is respiratory distress [4] [5]. Until recently, SAM management has been restricted to inpatient treatment, limiting its coverage and impact. With the community-based approach, introduced by WHO and UNICEF, a large number of children with severe acute malnutrition can be treated in their communities with ready-to-use therapeutic foods or other nutrient dense foods at home, without being admitted to a health facility or a therapeutic feeding centre. But in developing countries, first-level health facilities and community level care setting are generally run by "not physicians" medical staff and resources are limited for treatment. There is a need to give guidelines to first level and community cares providers when they have to treat severely malnourished children with anemia. Guidelines must be based on recommendations and evidences. This study aimed to analyze the impact of anemia on mortality rate and nutritional recovery, during severely malnourished inpatient treatment.

\section{Material and Methods}

\subsection{Study Design and Site}

This was a retrospective cohort study conducted from data of severely malnourished children hospitalized, between 2008 and 2009, at a feeding therapeutic center, based on inpatient treatment approach, in Ouagadougou. At this center, trained care providers staff, leaded by a medical doctor, was in charge of the treatment. Case management and follow-up care were based on WHO guidelines for inpatient treatment of severely malnourished children.

\subsection{Study Population}

The study concerned under five children, hospitalized for severe acute malnutrition (SAM). During the considered period, SAM diagnostic was based on severe wasting, as a weight-for-height below -3 SD or below $70 \%$ of median (based on NCHS reference) or the presence of nutritional edema affecting both feet. All patients received standard inpatient treatment for severely malnourished children with initial stabilization phase with F75 formula and rehabilitation phase with F100 formula. Treatment procedures were similar for Marasmus and kwashiorkor. Stabilization phase was without iron and iron was added in the rehabilitation phase. After admission, severely malnourished children parents are informed in the intra-hospital treatment process.

\subsection{Study Sample Size}

During the considered period, a total of 245 hospitalized severely malnourished children have been tested for hemog- lobin in total blood at admission. Data of these 245 severely malnourished children have been considered for analysis in this study.

\subsection{Data Collection}

Trained research nurses collected data on children's socio-demographic (sex, age), anthropometry at admission. The child age was determined using date of birth recorded from its mother pregnancy card and date of admission. 
Weight was measured in kg using recommended scale with a precision of $0.1 \mathrm{~kg}(100 \mathrm{~g})$. Length of less than 02 years old child was measured in centimeters using length board (horizontal infantometer) with a precision 0.1 $\mathrm{cm}(1 \mathrm{~mm})$ and height of 2 years or older child able to stand was measured in $\mathrm{cm}$ using height board (vertical stadiometer) with a precision $0.1 \mathrm{~cm}(1 \mathrm{~mm})$. If the child was not able to stand for any reason, length was measured using length board and subtract $0.7 \mathrm{~cm}$ to convert in to height. Edema of both feet was automatically considered as severely malnourished case. Hemoglobin testing is done in routine. There is no need of parents consent. Hemoglobin testing has been performed for children at Ouagadougou pediatric hospital laboratory. Child blood samples were collected and identified by a single code and immediately transferred for analyze. At admission, children anemia was defined severe when hemoglobin $(\mathrm{Hb})$ was $<6 \mathrm{~g} / \mathrm{dl}$, moderate when $\mathrm{Hb}$ was between 6 $-11 \mathrm{~g} / \mathrm{dl}$.

\subsection{Statistical Analyses}

Usual statistics methods were applied. We used Pearson's Chi square test or Fisher's exact test to compare proportions; and Student's independent t-test to compare means. General linear model has been used to analyze, from repeated measurements of anthropometry data, impact of anemia status at admission on nutritional recovery. Mortality relative's risks with confidence interval (CI95\%) have been calculated to estimate the impact of anemia on mortality rate. Kaplan-Meir survival curves have been used to investigate the impact of anemia on mortality rate.

The following lower and upper standard deviation (SD) boundaries have been used: Weight-for-height Z-score (WHZ) $(-4,+6)$, and Weight-for-age Z-score (WAZ) $(-6,+6)$.

The data were analyzed using SPSS software version 20.

\section{Results}

At admission, $85.3 \%$ of included malnourished children had anemia $(\mathrm{Hb} \leq 11 \mathrm{~g} / \mathrm{dl})$ and $10.6 \%$ severe anemic $(\mathrm{Hb}<6 \mathrm{~g} / \mathrm{dl})$. The children mean age was 17.44 (8.51) months. From anthropometry, mean weight-for-height Z-score (WHZ) (-3.43 (0.87)), mean weight-for-age Z-score (WAZ) (-4.26 (0.98)) are showed on Table 1.

Hospitalization mean time was 20.47 (13.66) days. There was no statistic difference between the hospitalization mean time of malnourished children with anemia ((21.96 (12.2)) and those without anemia (21.42 (16.9)) at admission, $\mathrm{p}=0.8$. during the hospitalization time, no anemic malnourished children received blood transfusion.

During hospitalization, case fatality rate was $13.9 \%$. Mortality rate did not differed significantly from severely malnourished children with anemia at admission (12.4\%) and severely malnourished children without anemia at admission (22.2\%), $\mathrm{p}=0.12$. Mortality relative risk was $0.56,95 \% \mathrm{CI}=[0.28-1.14]$, for severely malnourished children with anemia at admission. Kaplan Meir survival curves did not differed significantly between the two groups, (p Log Rank = 0.11) (Figure 1).

From admission to discharge, anthropometric Z-scores means evolution did not differed significantly between severely malnourished children with and without anemia at admission. But anthropometric Z-scores means evo-

Table 1. Children characteristics at admission.

\begin{tabular}{|c|c|c|c|}
\hline & $\mathbf{N}$ & Percentage (\%) & Mean (SD) \\
\hline Age (months) & 245 & & $17.44(8.51)$ \\
\hline WHZ & 245 & & $-3.43(0.87)$ \\
\hline WAZ & 245 & & $-4.26(0.98)$ \\
\hline HAZ & 245 & & $-2.70(1.37)$ \\
\hline \multicolumn{4}{|l|}{ Sex } \\
\hline Boys & 145 & 59.2 & \\
\hline Girls & 100 & 40.8 & \\
\hline \multicolumn{4}{|l|}{ Anemia } \\
\hline Severe & 26 & 10.6 & \\
\hline Moderate & 183 & 74.7 & \\
\hline Normal & 36 & 14.7 & \\
\hline
\end{tabular}




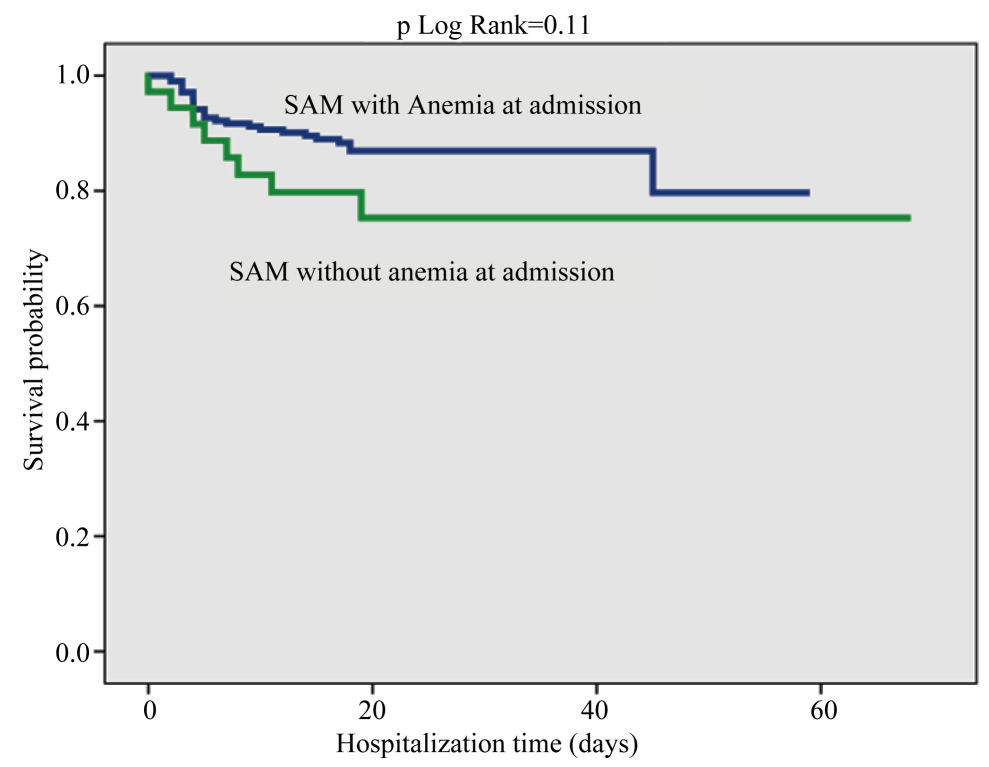

Figure 1. Kaplan Meir survival of severely malnourished children with and without anemia at admission.

lution differed significantly within each group's subjects: WHZ (between groups: $\mathrm{p}=0.74$; within subjects: $\mathrm{p}<$ 0.001), (Figure 2) and WAZ (between groups: $\mathrm{p}=0.54$; within subjects: $\mathrm{p}<0.001$ ) (Figure 3).

\section{Discussion}

This study aimed to analyze the impact of anemia on mortality rate and nutritional recovery, during severely malnourished inpatient treatment.

At admission, from the 245 severely malnourished children, 85.3\% were anemic. Children anemia has multiple and synergetic causes including malnutrition, infectious diseases, malaria [6] [7].

In a context of high prevalence of anemia and high prevalence of severe malnutrition, anemia between severely malnourished children is common as reported by several observational studies [1]-[3] [8].

If not adequately managed, anemia can be responsible for increased mortality in severely malnourished children [9] [10].

In Our study, strongly respect of current recommendation to not add iron supplementation at stabilization phase of severe malnutrition inpatient treatment, but add iron at rehabilitation phase [11], did not showed increased mortality rate in SAM anemic group. Generally, it is not easy to realize blood transfusion in our context, there is scars availability of blood due to limited blood donation. At admission, $10.6 \%$ of SAM children were severe anemic. They did not receive blood transfusion, but did not show increased mortality.

In our study, at discharge, anthropometric Z-scores means evolution (WHZ and WAZ), did not differed significantly between anemic and non anemic severely children, but within subjects of each group, anthropometric Z-scores means evolution differed significantly. It is meaning that with a strong respect of current inpatient SAM management, anemia did not have negative impact on nutritional recovery during hospitalization. In low income countries, a large number of ill children did not attend first level facilities for many poverty socioeconomics related factors. From those attending the first level health facilities, for a large number, even if necessary, referral will not be possible [12] [13]. All of these ill children will be treated at first level facilities or at community level. The challenge is great in management of anemic severely malnourished children at community or first-level health facilities of low income countries when referral is not possible. At these levels, a child with palmar pallor may have anemia and should be given systematically iron, antimalarial and the child should also receive treatment for hookworm and whipworm; all children with severe anemia must be referred urgently to hospital because they may need blood transfusions. Lack of skilled or trained care providers on severely malnourished children treatment can increase mortality risk. Our find showed that anemia did not increase mortality risk if recommendations are strongly respected (add iron, not at stabilization phase of severe malnutrition treat- 


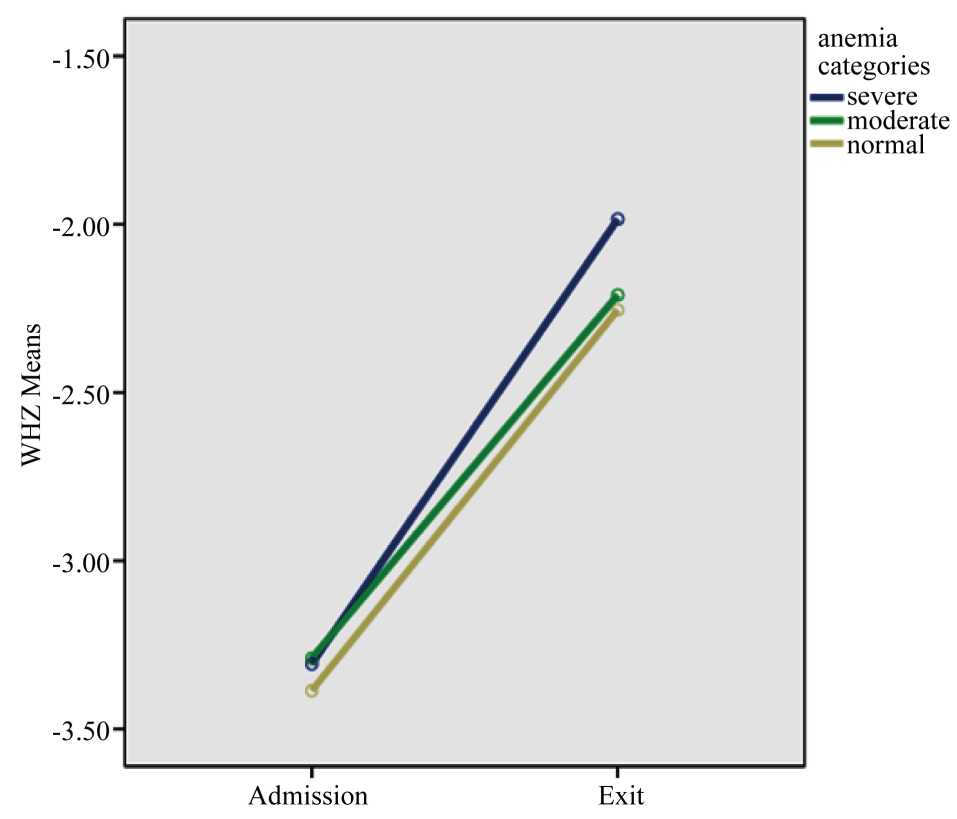

Figure 2. Z-WHZ means evolution from admission to discharge between groups and within each group subjects.

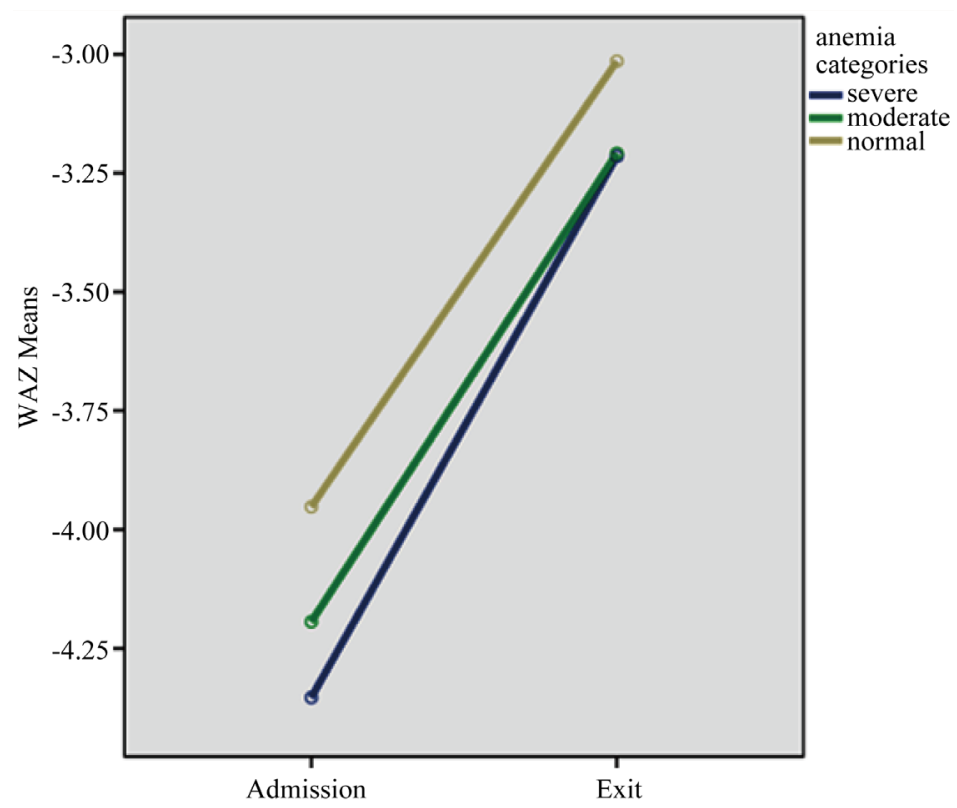

Figure 3. Z-WAZ means evolution from admission to discharge between groups and within each group subjects.

ment, but at rehabilitation phase); and that nutritional recovery is significant within subjects of SAM anemic and non anemic children, without difference between groups. There is an urgent need to update guidelines for anemia treatment at community and at health first level facilities in a context of high prevalence of severe malnutrition and lack of referral.

\section{Conclusion}

With a strong respect of current recommendation of anemia treatment of inpatient severely malnutrition management, there is no increased mortality rate in SAM anemic group; and nutritional recovery is significant with- 
in subjects of SAM anemic and non anemic children, without difference between groups.

\section{Acknowledgements}

Commission Universitaire pour le Développement (CUD), Belgique

\section{References}

[1] Thakur, N., Chandra, J., Pemde, H. and Singh, V. (2013) Anemia in Severe Acute Malnutrition. Nutrition, 30, $440-442$. http://dx.doi.org/10.1016/j.nut.2013.09.011

[2] Thorne, C.J., Roberts, L.M., Edwards, D.R., Haque, M.S., Cumbassa, A. and Last, A.R. (2013) Anaemia and Mal- nutrition in Children Aged 0-59 Months on the Bijagós Archipelago, Guinea-Bissau, West Africa: A Cross-Sectional, Population-Based Study. Paediatrics and International Child Health, 33, 151-160. http://dx.doi.org/10.1179/2046905513Y.0000000060

[3] De Fátima Costa Caminha, M., Da Figueira, M.A., Falbo, A.R., De Araújo de Amorim, R.C., Gallindo, T.C. and Filho, M.B. (2011) Co-Existence of Micronutrient Deficiencies in Hospitalized Children with Severe Malnutrition Treated According to the WHO Protocol. Tropical Doctor, 41, 230-232. http://dx.doi.org/10.1258/td.2011.100140

[4] WHO (2001) Management of the Child with a Serious Infection or Malnutrition. Guideline for Care at the First Referral Level in Developing Countries. World Health Organization, Geneva.

[5] WHO (2013) Guideline: Updates on the Management of Severe Acute Malnutrition in Infants and Children. World Health Organization, Geneva.

[6] Balarjan, Y., Ramakrishnan, U., Ozaltin, E., Shankar, A.H. and Subramanian, S.V. (2011) Anaemia in Low-Income and Middle-Income Countries. Lancet, 378, 2123-2135. http://dx.doi.org/10.1016/S0140-6736(10)62304-5

[7] Osazuwa, F. and Ayo, O.M. (2010) Contribution of Malnutrition and Malaria to Anemia in Children in Rural Communities of Edo State, Nigeria. North American Journal of Medical Sciences, 2, 532-536. http://dx.doi.org/10.4297/najms.2010.2532

[8] Yang, W., Li, X., Li, Y., Zhang, S., Liu, L., Wang, X. and Li, W. (2012) Anaemia, Malnutrition and Their Correlations with Socio-Demographic Characteristics and Feeding Practices among Infants Aged 0-18 Months in Rural Areas of Shaanxi Province in Northwestern China: A Cross-Sectional Study. BMC Public Health, 12, 1127. http://dx.doi.org/10.1186/1471-2458-12-1127

[9] Bachou, H., Tumwine, J.K., Mwadime, R.K.N. and Tylleskär, T. (2006) Risk Factors in Hospital Deaths in Severely Malnourished Children in Kampala, Uganda. BMC Pediatrics, 6, 7 http://dx.doi.org/10.1186/1471-2431-6-7

[10] Muoneke, V.U., Ibekwe, R.C., Nebe-Agumadu, H.U. and Ibe, B.C. (2012) Factors Associated with Mortality in UnderFive Children with Severe Anemia in Ebonyi, Nigeria. Indian Pediatrics, 49, 119-123. http://dx.doi.org/10.1007/s13312-012-0026-4

[11] Ashworth, A., Khanum, S., Jackson, A. and Schofield C. (2003) Guidelines for the Inpatient Treatment of Severely Malnourished Children. WHO, Geneva.

[12] Simoes, E.A., Peterson, S., Gamatie, Y., Kisanga, F.S., Mukasa, G., Nsungwa-Sabiiti, J., Were, M.W. and Weber, M.W. (3003) Management of Severely Ill Children at First-Level Health Facilities in Sub-Saharan Africa When Referral Is Difficult. Bulletin of the World Health Organization, 81, 522-531.

[13] Kahigwa, E., Schellenberg, D., Sanz, S., Aponte, J.J., Wigayi, J., Mshinda, H., Alonso, P. and Menendez, C. (2002) Risk Factors for Presentation to Hospital with Severe Anaemia in Tanzanian Children: A Case-Control Study. Tropical Medicine and International Health, 7, 823-830. http://dx.doi.org/10.1046/j.1365-3156.2002.00938.x 